\title{
Die Ebstorfer Weltkarte. Die größte Karte des Mittelalters
}

\section{Christoph Mauntel}

\section{OpenEdition \\ Journals}

Édition électronique

URL : http://journals.openedition.org/ifha/10842

DOI : $10.4000 /$ ifha. 10842

ISSN : 2198-8943

Éditeur

IFRA - Institut franco-allemand (sciences historiques et sociales)

\section{Référence électronique}

Christoph Mauntel, «Die Ebstorfer Weltkarte. Die größte Karte des Mittelalters », Revue de l'IFHA [En ligne], Date de recension, mis en ligne le 16 juillet 2020, consulté le 24 septembre 2020. URL : http:// journals.openedition.org/ifha/10842 ; DOI : https://doi.org/10.4000/ifha.10842

Ce document a été généré automatiquement le 24 septembre 2020.

(C)IFHA 


\title{
Die Ebstorfer Weltkarte. Die größte Karte des Mittelalters
}

\author{
Christoph Mauntel
}

\section{RÉFÉRENCE}

Die Ebstorfer Weltkarte. Die größte Karte des Mittelalters. Kommentierte Neuausgabe in zwei Bänden, éd. Hartmut Kugler, Darmstadt, Wissenschaftliche Buchgesellschaft, 2020, $200 €$ 
La carte du monde d'Ebstorf est, comme l'énonce le sous-titre de l'ouvrage, "la plus grande carte du Moyen Âge ». Elle se composait de 30 morceaux de parchemin collés et mesurait environ 3,6 × 3,6 mètres. Une mappemonde ronde, entourée de textes explicatifs sur la structure du monde et de nombreux peuples et animaux sauvages, montrait le monde selon les idées médiévales : orienté à l'est et divisé en trois continents par le schéma en T. L'Asie occupait sa moitié orientale, l'Afrique et l'Europe se partageaient l'ouest.

Le livre en deux volumes et grand format présente cette carte en l'enrichissant d'un commentaire et d'illustrations détaillées ainsi que d'une transcription et d'une

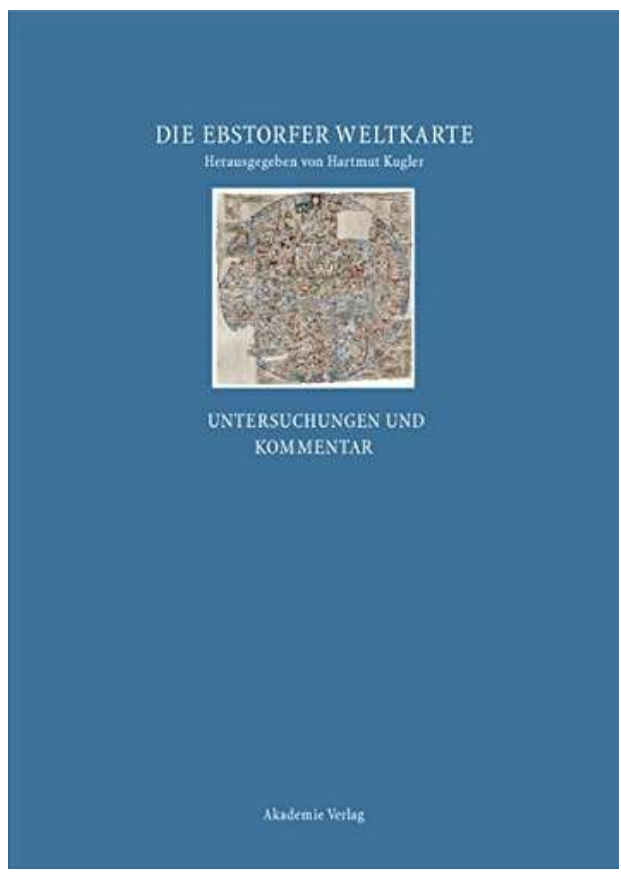
traduction allemande des 1500 légendes latines. Il s'agit ici d'une réimpression de l'édition critique de la carte d'Ebstorf publiée par Hartmut Kugler en 2007. À l'exception d'une nouvelle préface introductive de l'historien de l'art de Bonn Harald Wolter-von dem Knesebeck, la nouvelle édition est identique dans son contenu à celle de 2007.

Le premier volume représente l'édition en elle-même. Afin de maîtriser l'énorme carte, Kugler l'a divisée en 61 planches, elles-mêmes divisées en quatre sections et traitées successivement. Chaque planche présente une reproduction agrandie et la transcription des légendes. Cette approche conduit à une codification peu intuitive : la légende de la ville de Jérusalem (IHERUSALEM) au centre de la carte se trouve sous 32 (planche), A1 (section de planche 32), 3 (troisième légende de planche 32) (à la page 92-93). Il aurait peut-être été plus facile et plus précis d'attribuer un numéro de série à chaque légende - comme l'a fait Piero Falchetta dans son édition de la mappemonde du cartographe Vénitien Fra Mauro (Brepols, 2006). Bien entendu, cette critique s'adresse à l'édition de 2007 et non à la présente réimpression.

Le deuxième volume offre une introduction détaillée de la carte d'Ebstorf (p. 1-69): $\mathrm{H}$. Kugler prend pour sujet la transmission, la structure et la conception visuelle, les sources, les questions de la datation et de la paternité littéraire. De fait, la carte fut découverte en 1830 seulement, dans une chambre du monastère de moniales d'Ebstorf, où elle avait été oubliée pendant des siècles après y avoir été fabriquée "vers 1300 " (p. 69). En 1943, l'original de la carte brûla lors d'un bombardement sur Hanovre. Son auteur est inconnu (on l'a longtemps attribuée au clerc anglais Gervais de Tilbury, mais cette thèse a été réfutée), mais on peut distinguer huit différents scribes (Wilke 2001). Les sources de la carte sont principalement des encyclopédies médiévales traditionnelles: celles d'Isidore de Séville, d'Honoré d'Autun ou d'autres textes. La carte est donc fermement ancrée dans un horizon de connaissances géographiques traditionnelles et n'est pas encore affectée par les récits des voyageurs qui ont commencé à explorer l'Asie vers 1240. De fait, la mappemonde représente des endroits bibliques ou chrétiens (comme le paradis, l'arche de Noé ou la tour de Babel), des lieux 
légendaires (tels que ceux de l'histoire d'Alexandre le Grand) et des peuples et créatures mythiques (comme les Amazones ou des humains avec des déformations physiques/des monstres). L'empreinte chrétienne profonde de la carte se révèle aussi dans la figure du Christ qui l'entoure sur les quatre côtés. La majeure partie du deuxième volume est constituée d'un commentaire détaillé des légendes (en allemand) (p. 71-332). Les commentaires citent les sources et les références de la légende auxquelles ils se rapportent, traitent des représentations d'animaux, de villes et d'autres êtres et renvoient à des sources parallèles. Le volume se conclut par des listes de sources et de registres.

L'édition de Kugler est d'une grande valeur pour la recherche historique, la nouvelle réimpression la rend de nouveau accessible - au prix cependant élevé de 250 euros. Même si la carte est très bien présentée sur un site Internet (https:// warnke.web.leuphana.de/hyperimage/EbsKart/index.html\#09999/), la version en ligne ne peut pas encore remplacer la version imprimée. C'est pourquoi il serait souhaitable que le site Internet soit harmonisé aux codifications de l'édition de Kugler (en ligne, Jérusalem se trouve sous le la cote V18_028). Mais ne serait-il pas follement audacieux, en 2020 et en pleine crise du coronavirus, de réfléchir à la manière dont des cartes historiques, telles que la mappemonde d'Ebstorf, pourraient faire l'objet d'une édition scientifique en ligne?

\section{INDEX}

Index chronologique : Moyen Âge

Thèmes : histoire des mentalités

\section{AUTEURS}

\section{CHRISTOPH MAUNTEL}

Eberhard Karls Universität Tübingen

Institut d'histoire médiévale 